\title{
Excess Coalbed Methane Production Mechanism in the Process of Coal Tectonic Deformation
}

\author{
Yi Luo, Shuying Li \\ National Geological Library of China, Beijing, China \\ Email: 111985125@163.com
}

Received 11 July 2016; accepted 27 July 2016; published 30 July 2016

\section{Abstract}

Source and occurrence of Excess Coalbed Methane is a long-term concern research topic in Coal Geology and Structural Geology. Since it is essential to understand the outburst mechanism of coal gas, and to support the coalbed methane development projects as the theoretical basis. We found in the study that, huge imparity is behind the evolutionary trend on molecular structure and the mechanism of influence from different deformation. The thesis demonstrates its probable routes of gas evolution according to distinct deformation mechanisms of coal. In the role of brittle deformation mechanism, a rapidly formed advantage rupture surface along with sliding motion from which has worked on coal. As another result, mechanical energy has transformed into friction and kinetic energy during the process. Kinetic energy increases simultaneously, which brings some results, that the new generated gas molecule. While the chemical structure of coal remains in a steady-state and do not react easily an outburst with gas. Mechanical energy turns into strain energy through its ductile deformation mechanism. The dislocation or lamellar slip made disordered between the constitutional units of aromatic rings and aromatic lamellas, as soon as secondary structural defects created. On another hand, molecular motion accelerates and splits off the small molecular on the side chain, due to the dissociation of aromatic nucleus; $\mathrm{CH}_{4}$ gas molecular was generated and placed in the secondary structural defect of coal, along with a great deal of strain energy in non-steady-state. By breaking away the balance maintaining terms, huge strain energy releases suddenly, small moleculars are free from the secondary structure defect, react outburst with gas. Furthermore to extend the discussion of the conventional physical ideas on coal absorb gas, according to the phenomenon of exceeded CBM, the gas molecular has a significant chance existing in a low bond energy of chemical bonds of coal structure.

\section{Keywords}

Tectonic Coal, Gas Generation by Deformation, Mechanism of Gas Generation

\section{Propose a Question}

Coalbed methane (i.e. coal mine gas), which mainly consists of methane, is one kind of gaseous geological body

How to cite this paper: Luo, Y. and Li, S.Y. (2016) Excess Coalbed Methane Production Mechanism in the Process of Coal Tectonic Deformation. Journal of Geoscience and Environment Protection, 4, 175-178. 
that is generated and reserved mainly by adsorption in coalbed. It is a clean and efficient energy, and yet it is a major mine hazard. Research demonstrates that coal and gas outburst has a close relationship with tectonic deformation.

Roughly, almost all coal and gas outbursts around the world occurs in intense tectonic deformation coals, meanwhile, the amount of gas outburst is generally several to hundreds of times higher than the max-adsorption of coal, which cannot be reasonably explained only as absorbed gas in wall rocks. Peng Lishi et al. (1988) [1], Hou Quanlin et al. (1995) [2], Ju et al. (2002, 2005) [3] [4], Cao et al. (1996, 2006) [5] [6] and Wang Zhirong et al. (2006) [7] research the Bedding sliding structure of coal control to the gas outburst and point out that the strong tectonic shear, especially in coal seam shear zone, often have gas outburst areas, such as Baijiao coal mine in Sichuan.

2092 face seam shear zone in Baijiao have seven gas outburst one after another (Figure 1). Li Peking on the basis of analysis of the Chongqing area of coal and gas prominent feature, pointed out that the geological structure is the main factors affecting the coal and gas outburst [8] [9].

According to incomplete statistics, almost all of the world's coal gas outburst occurred in transformation coal transformed by intensive tectonic movement, although not all of tectonic coal occurrence of coal and gas outburst, Generally tectonic coal is not necessarily for gas outburst, non-deformed coal certain not gas outburst, gas outburst must be constructed coal. So, what kind of tectonic coals are more prone to gas outburst?

The above discussion objectively raises an important question for coalfield geology and structural geology: is there a relationship between the excess coalbed methane and coal deformation, and if it is related, what is the relationship. Without any doubt, the better understanding of this issue will play a significant role in understanding the mechanism of coal and gas outburst and coalbed methane exploration. Sub-high-temperature and subhigh-pressure deformation experiments on middle-rank coals were designed in our work, combined with gas composition analysis, quantitative analysis of hydrogen and carbon elements, and Fourier transform infrared spectrometer (FTIR). Based on our achievements, this dissertation presents whether middle rank coal can generate methane during the deformation process and if and how the chemical structure will change during this process.

\section{Excess CBM Possible Source}

We designed an experiment to study the gas generation during deformation. To exclude the impact of pyrolysis
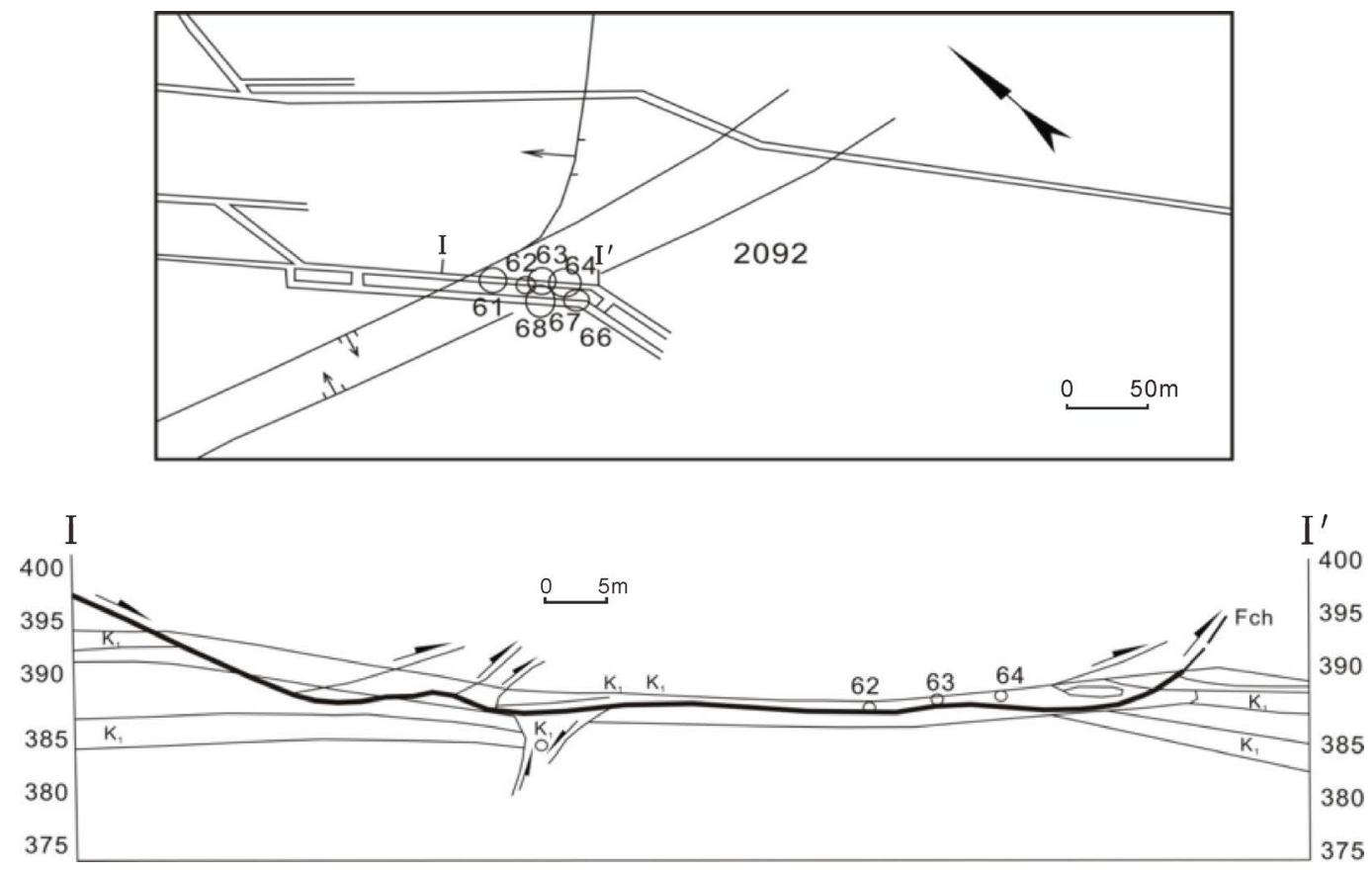

Figure 1. Baijiao coal mine in Sichuan 2092 Face of Outburst with flat and sections. 
gas, the experimental temperatures were only $70^{\circ} \mathrm{C}$ and $100^{\circ} \mathrm{C}$, which are far below the pyrolysis temperature of sample coals [10]. Meanwhile, we eliminated the impact of residual gas in coals to the greatest extent, in order to test the gas during deformation precisely. Results show that, the experiment is feasible in studying whether coals can generate gas during the deformation process. During the deformation of middle-rank coals new methane will be generated and gas generation is affected both by the experimental temperature and differential stress and the latter outweighs. The gas shows an increasing trend with the reinforcement of differential stress. By contrast, the temperature affects the amount of gas by affecting the deformation behavior of coal since it can improve the ductile deformation and thus facilitates gas generation.

Quantitative analysis of hydrogen and carbon elements is performed on samples before and after the deformation. The results reveal that hydrogen and carbon elements of all samples decline in some degree after the deformation experiments and the reduction of hydrogen and carbon shows a good corresponding relationship with the deformation and the new generated methane. When the experimental temperature is the highest and the differential stress is the biggest, the decline is the max and the gas is the most. The result on the one hand explains that the gas collected in the experiments is neither residual gas nor from small inclusions, but comes from coals' chemical structure, on the other hand demonstrate that the deformation under tectonic stress can not only change the physical structure of coal, but also change its chemical structure, and thus contributes to the generation of methane.

Evidence provided by Fourier transform infrared spectrometer (FTIR) shows that the content of aliphatic groups decreases [11]-[14], while the aromatic and naphthenic groups stay steady. Methyl is very sensitive to differential stress, and the specific performance is that even a small differential stress will result a large loss of methyl. The decrease of methyl shows a good corresponding relationship with the methane. The peak area of G which belongs to the total number of aromatic rings increases both with the differential stress and the temperature, but it is more sensitive with the differential [15]. The peak area of D which relates with structural imperfection of coal molecular is very sensitive to ductile deformation, since when the experimental condition is in favor of ductile deformation, the peak area of $\mathrm{D}$ increases markedly. The feature of Raman spectra proves the dynamic metamorphism of coals, that is to say, the deformation can change the chemical structure of coals, improve the degree of coalification, promote the loss of side chain and functional groups, thus facilitates the molecule structure to be aromatic.

\section{Discussion}

In the end, we discuss the controlling mechanism of ductile deformation to coal chemical structures and gas generation. Under brittle deformation conditions, samples deform with the characteristics of fracture and grinding, forming obviously sliding advantage failure surface and the change of chemical structure is caused by kinetic energy, which is transformed primarily by mechanical friction between fractures. Along with enhanced deformation, thermal energy is accumulated and the molecular activity within coals is increased which cause functional groups and aromatic chain to pyrolyze and shed successively on the basis of the bond energy, companying with small quantity of methane emission. On the other hand aromatic nuclei grow up and polycondensation is enhanced. However, the chemical structure of coal is still in the steady state, so it is not prone to outburst. Under ductile deformation mechanism, effect of tectonic stress on coals mainly converts into strain energy which can promote coal molecular units to deform, break and bring about dislocation and creep of coal interior nucleus. This process, on the one hand, results in the increase of structural imperfection and the decrease of polycondensation, on the other hand, causes the aromatic chain to shed along with gas generation. The gas as well as unsteady strain energy is stored in the imperfect structure. When the equivalent condition is broken, enormous strain energy and excess coalbed methane will be generated from the structural imperfection. This may be the dynamic process of coal and gas outburst.

\section{References}

[1] Peng, L.S. and Chen, K.D. (1988) Role of Slip Sheet Structure in the Mechanism of Coal/Gas Outburst. Journal of Jiaozuo Mining Institute, 12-13, 156-164.

[2] Hou, Q.L., Li, P.J. and Li, J.L. (1995) Foreland Fold-Thrust Belt of the Southwest of Fujian. Geological Publishing House, Beijing.

[3] Ju, Y.W. and Wang, G.L. (2002) Rheology of Coal Seams and Their Relation with Gas Outbursts: A Case Study of the 
Haizi Coal Mine, Huaibei Coalfield. Geological Review, 48, 96-105.

[4] Ju, Y.W., Jiang, B., Hou, Q.L., Wang, G.L. and Fang, A.M. (2005) Structural Evolution of Nano-Scale Pores of Tectonic Coals in Southern North China and Its Mechanism. Acta Geologica Sinica, 79, 269-285.

[5] Cao, Y.X., Zhang, Y.G. and Li, K.Q. (1996) Tectonic Coal Dynamometamorphism and Evolutionary Process. Coal Geology \& Exploration, 24, 15-17.

[6] Cao, D.Y., Li, X.M. and Zhang, S.Y. (2006) The Influence of Structural Stress on Coalification: The Stress Degradation Mechanism and the Stress Polycondensation Mechanism. Science in China Series D: Earth Sciences, 36, 59-68.

[7] Wang, Z.R., Lang, D.S., Liu, S.J., Cheng, C.R. and Chen, L.X. (2006) Tectonic Control on Gas Geological Hazard in Liudian Gliding Structure. Journal of China Coal Society, 31, 553-557.

[8] Zhang, X.B., Zhang, Z.M. and Zhang, Y.G. (2009) Mechanochemical Action and Deformed Coal Structure. Coal Geology of China, 21, 10-14.

[9] Zhang, Y.G., Zhang, Z.M. and Cao, Y.X. (2007) Deformed-Coal Structure and Control to Coal-Gas Outburst. Journal of China Coal Society, 32, 281-284.

[10] Wu, J. (1987) Study on Micro-Structure and Surface Features of Coal Prone to Outburst. Journal of China Coal Society, 2, 40-46.

[11] Li, X.S., Ju, Y.W., Hou, Q.L. and Lin, H. (2010) Influence Mechanism of Tectonic Deformation on Macromolecular Chemical Structure of Coals: A Case Study of Vitrinite Separation of Tectonically Deformed Coals. Journal of China Coal Society, 35, 150-157.

[12] Li, X.S., Ju, Y.W., Hou, Q.L. and Lin, H. (2011) Spectrum Research on Metamorphic and Deformation of Tectonically Deformed Coals. Spectroscopy and Spectral Analysis, 31, 2176-2182.

[13] Jiang, B., Qin, Y. and Jin, F.L. (1998) XRD Analysis of the Structural Evolution of Deformed Coal Samples Tested Under High Temperature and High Confined Pressure. Journal of China Coal Society, 23, 188-193.

[14] Jiang, J.P., Luo, G.Y. and Kang, J.W. (2001) Study on XRD and Dynamometamorphism of Fault Coal. Journal of China Coal Society, 26, 31-34.

[15] Lin, H., Ju, Y.W., Hou, Q.L., Li, X.S., Wu, Y.D., Tan, J.Q. and Fan, J.J. (2009) The Characteristics of Laser Roman Spectroscopy and Response of Structural Components Construction of the Brittle and Ductile Deformed Coals. Progress in Natural Science, 19, 1117-1125.

\section{Submit or recommend next manuscript to SCIRP and we will provide best service for you:}

Accepting pre-submission inquiries through Email, Facebook, LinkedIn, Twitter, etc.

A wide selection of journals (inclusive of 9 subjects, more than 200 journals)

Providing 24-hour high-quality service

User-friendly online submission system

Fair and swift peer-review system

Efficient typesetting and proofreading procedure

Display of the result of downloads and visits, as well as the number of cited articles

Maximum dissemination of your research work

Submit your manuscript at: http://papersubmission.scirp.org/ 